\title{
Weblogs and Journalism
}

\author{
A Typology to Explore the Blurring Boundaries
}

\author{
David Domingo \& Ari Heinonen
}

\begin{abstract}
From the perspective of journalism, weblogs can be seen as a new category of news and current affairs communication. Although most weblogs do not even pretend to be journalistic or related to current events in the sense shared by institutional media, when bloggers approach the arena of journalism, some of their working principles can challenge traditional professional standards: Conversation with the audience, transparency in the reporting process or even participatory news production are common in blogging. By challenging the conventional understanding of what journalism is, weblogs have revitalized the voices that expect a paradigm shift in journalism in the Internet era. In order to contribute to the debate on the influences of weblogs on journalism and make it more systematic, we propose a typology of journalistic weblogs, along a continuum ranging from the least to the most institutionalized in terms of their relationship to the established media: At one end, we find weblogs produced by the public outside media companies, and at the other end, we find those that are part of media content and produced by professional staff journalists. We argue that weblogs are a symbol of the ongoing change in the relationship between citizens, media and journalists - a change that questions the basic assumptions of the traditional roles of institutional journalism.
\end{abstract}

Keywords: weblog, blogger, active audience, citizen journalism, professional journalism

\section{Introduction}

The debate about whether weblogs are of significance from the perspective of journalism has changed its tune. Instead of wondering whether weblogs are of importance to journalism, the question being asked at the moment is how important weblogs are (Lowrey, 2007). Today, weblogs seem to be everywhere in and around journalism: The media publish weblogs as one item in their online content repertoire, individual journalists have taken up blogging, and an array of amateurs (with regard to journalism) are maintaining weblogs that at least to a certain extent resemble news journalism.

Although lately much has been said about weblogs as a phenomenon, and descriptions of the rise of the "blogosphere" have been abundant both in scholarly and journalistic trade journals, analytical treatises on the relationship between weblogs and journalism have been less frequent. Admittedly such valuable contributions to this end, such as Matheson's (2004a,b), Singer's (2005) or Lowrey's (2006), have outlined the borderland between blogging in general and blogging related to journalism, but their starting point has been a discussion of weblogs as a new genre of online publishing. Our perspective arises from 
an interest in what is happening to journalism and its position in society at this point in time. Thus, the focus here is purposefully on a fraction of the blogosphere - that of relevance to journalism and journalistic media - with an aim to contribute to the debate about the future of journalism in the age of networked communication.

To accomplish this task, this article tries to systematize what we call journalistic weblogs into a typology. Our goal is to provide at least some kind of order in a seemingly entangled discussion on weblogs and journalism, and hence hopefully to make a fresh contribution to the ongoing debate on the challenges that the blogosphere poses to professional journalism. In order to avoid treating weblogs as something unconnected and unhistorical, we firstly place weblogs in the wider perspective of online journalism history, and then look into the defining characteristics of weblogs themselves. Equipped with the typology drawn from this context, we shall consider the significance of weblogs to journalism. Our main argument is that weblogs are important not only as such, but even more as a sign of an emerging new category of news and current affairs communication that challenges the conventional understanding of journalism.

\section{Prophecies on the Internet and Journalism}

The fundamental idea behind weblogs - that of a more democratic type of publishing - is in fact quite old, at least in terms of the Internet era. In the mid-90s, the World Wide Web seemed to be revolutionizing the communication environment. With relatively easy-to-use html editors, global (and local) publishing became a reality for those masses who had thus far been relegated to the role of passive receivers in a communication process dominated by institutional media. The web was seen to herald the dawn of a more varied communication setting in a true "Castellsian" sense: Instead of one-way communication flows, from a few central points to countless receivers, there would be a network of communication flows between equally influential nodes capable of acting both as senders and receivers of information (Castells, 1996; Heinonen, 1999:28).

In many cases, this horizontality was considered a threat to conventional journalism: "Everything I've learned argues that digital technologies will continue to grow, eventually creating a new medium that will force all previous communications media to redefine themselves, just as radio had to do when television came along" (Fulton, 1996). The vision was that in a few years industrial media and its journalism would wither away, while various many-to-many publishing networks would create a new egalitarian communication culture.

However, ten years after the first "Web-fever outbreaks", we can say that not that much has happened. Admittedly, the Internet has become a natural part of our global communication structure and there are numerous online publications by non-media publishers. In some cases, these have become channels of important communication, at least in some constituencies: The Independent Media Centre is an outlet for anti-globalization activist media (Hyde, 2001; Platon and Deuze, 2003), many local web publications experiment with new modes of citizen communication (Sirkkunen and Kotilainen, 2004; Schaffer, 2007), and some of the new net publications targeted at wider audiences have also found their publics. The institutional media have also established themselves online, some with more ambitious strategies, but most satisfied with re-cycling their offline contents into online versions of their outlets and reproducing traditional journalism routines and values in their purely digital content (see Paul, 2005; Van der Wurff and Lauf, 2005; Domingo, 2006). When it comes to audience participation, their strat- 
egy tends to replicate the gatekeeper model to user-generated content: filtering and separating it from the news produced by professionals (Hermida and Thurman, 2007). In essence, the big picture is that the Internet did not bring about the revolutionizing impact on journalistic communication that many had hoped and perhaps even more feared.

Now, along with weblogs, the debate on the possible paradigm shift in journalism has surfaced again, and not only owing to the introduction of a new publishing technology. In the United States particularly, one important driving force has been discontent with the performance of journalism by the established media (Deuze, 2005). It has been pointed out that journalism has distanced itself from civic society in its pursuit of nonpartisanship. "The profession has come to see its niche as connected to the often-misunderstood concept of objectivity, which refers not to the absence of personal bias but rather to journalistic method..." (Singer, 2005:177). Instead of being the fellow citizens of their readers, journalists (pre)tend to act like non-committed observers (Heinonen, 1999:19-20). The result has been that journalism is, from the point of the public, an institution somewhere out there with no real ties to its constituency.

It is reasonable to assume that the social maturation of Internet communication, for its part, has formed favourable ground for weblogs to develop as a specific net communication genre. Earlier web publications were either complicated to create (proper online newspapers, for instance) or rather simple and, thus, not terribly interesting (static personal home-pages, for instance). In addition, much of the contents on the Web were and continue to be modelled on older media, which is understandable because, as Fidler (1997) suggested, new media forms first imitate older ones before developing their own generic features. Weblogs appear to represent perhaps the first genre with a genuinely web-born format: "They are a media life form that is native to the Web, and they add something new to our mix ... something that couldn't have existed before the Web" (Rosenberg quoted in Lasica, 2003:72). Weblogs allow "...a form of writing that is unique to the web, reliant on what is arguably its key characteristic, hyperlink" (Matheson, 2004a:445).

\section{Features and Technology of Weblogs}

There are formal conventions in weblog production that distinguish them from other forms of serial online publishing. Simplicity is the rule. Posts are automatically organized in inverse chronological order and time-stamped. This means that the WWW homepage of a weblog will show first the last entry submitted by the author or authors. No journalistic criteria are used, for instance, in arranging the posts by relevance. They are published as they are produced. The relevance of a post is mostly external to the weblog, defined by the comments and attention it draws from the communities of bloggers.

Texts, the most common form of weblog posts, tend to be brief, direct and informal. In an information-saturated environment such as the Internet, users praise bloggers who express their ideas with no more words than are needed. Blogs are mostly written by one person and are regarded as personal spaces of self-expression. Therefore, interpretative and subjective style is the norm in weblog writing. Pictures, video and audio are still less common formats for posts, but blogs exist that are specialized in each of these: photoblogs, vlogs, audioblogs.

One of the most crucial attributes of weblogs is that they allow users to publish comments right below each post. This turns the blog into a debate arena in which the author initiates a conversation with a piece of information or opinion that the readers can fol- 
low up actively. In fact, the conversation extends to other weblogs: bloggers can comment on other weblog posts in their own blogs, and use a trackback tool to inform about their comment in the original post, with a link to their weblog. This way, blogs often form around them a community of users who contribute comments and of other bloggers who interconnect their posts in an ongoing conversation (Stauffer, 2002). This dialogical nature of weblogs is what makes them an appropriate tool with which to develop new kinds of participatory journalism projects, further developing public journalism exercises already undertaken in traditional media (see Kunelius, 2001).

Other common ingredients in weblog posts are hypertext links to websites and online documents the author refers to in the text. One of the reasons for this practice is that many weblogs concentrate on commenting on interesting content or initiatives that the blogger has found while surfing the Net. Offering a link to the content they are commenting on is an obvious choice in this case. The veteran blogger Rebecca Blood states that this practice has turned into a convention among bloggers because it increases the reliability of their posts. Moreover, she argued that "it ensures a level of accountability not found in traditional media" (Blood, 2002).

Most weblogs have very similar technological systems for managing production, editing and archiving of posts and comments. They have very user-friendly web-based interfaces with forms that the blogger completes to publish a post. There is no need for technical knowledge to set up a weblog. Blogging systems have evolved to allow users also to send their posts by e-mail or even SMS and MMS mobile messages to make publishing even faster and easier.

Weblogs have a specific format and specific software tools, but they also have certain distinctive cultural and behavioural features, and the latter define blogging as a genre as much as do the former. Personality or intimacy, communality, and specific style are key aspects of blogging. Thus, blogs are not just technical applications, but a set of socially defined habits. "Bloggers perceive themselves as part of a community that shares values, rituals and language" (Lowrey, 2006).

\section{A Typology of Journalistic Weblogs}

Not all weblogs pretend to be journalistic or related to current events in the sense shared by institutional media. In fact, most blogs are mainly personal and revolve around the feelings and experiences of the author. Only $34 \%$ of US bloggers surveyed by PEW Internet (Lenhart and Fox, 2006) considered their blogs a form of journalism. However, as Lasica (2002a) put it, any blogger can "commit journalism" when describing or analysing an event he/she has witnessed. In addition, after blogs became a buzzword within institutional media, some individual journalists also embraced them as a new, more open way to communicate with their audience. Subsequently, media companies themselves have explored the possibilities of this format as a journalistic genre and as an open space in which web users can participate. Even if bloggers writing about current events may not feel comfortable comparing their publishing to journalism (Matheson, 2004b), we argue that this heterogeneous group of weblogs, some made by the public, some by journalism practitioners, and some by media houses, have something in common that justifies the label "journalistic weblog": Although they may not strictly follow traditional journalistic routines and conventions, these weblogs have a clear intention to collect, analyse, interpret or comment on current events to wide audiences and in this way perform the very same social function usually associated with institutionalized media. 
In the following, we shall scrutinize journalistic weblogs by placing them on a continuum ranging from the least to the most institutionalized in terms of their relationship with the established media (Figure 1). Thus, at one end, we find weblogs produced by the public outside media companies (citizen blogs), and at the opposite end, we find weblogs that are part of media content and produced by professional staff journalists (media blogs). In the middle, there are weblogs that the audience can produce on platforms provided by the media (audience blogs), and weblogs that journalists maintain outside their companies (journalist blogs). In the following paragraphs, we will examine more thoroughly citizen blogs and media blogs, because their development seems to be most significant from the perspective of the change in journalism: Citizen blogs challenge journalism from the outside, without any of the constraints of the media institution, and media blogs transform journalism from the inside, which is relevant to understanding how professional newsrooms are "normalizing" (Singer, 2005) the new genre and embedding it in their production logics.

Every form has its specific characteristics, but what is important is that the level of affiliation to institutional media does not necessarily imply better credibility, accuracy or more influence. A multitude of factors contribute to the success of a journalistic weblog as a reliable source of information for the public, regardless of whether it is produced by a professional: perceived honesty, transparency of available information, regularity of updating, and relative topicality (which may vary according to the topic of the blog). Each type of journalistic weblog has its strengths and weaknesses compared to the traditional standards of the journalistic profession, and within every type there is also variation in content and quality. However, this typology helps us to assess the significance of weblogs to professional journalism.

Figure 1. Typology of Journalistic Weblogs

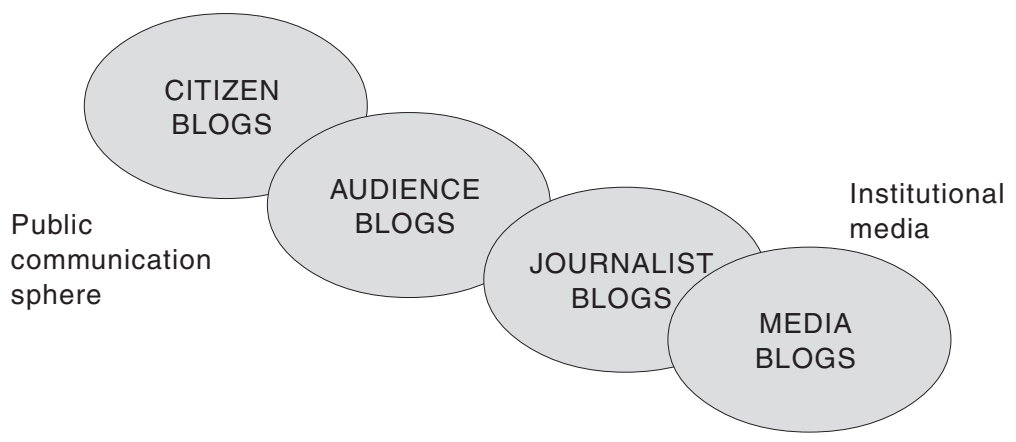

a) Citizen Blogs: Journalistic Weblogs Written by the Public Outside the Media When bloggers "commit journalism", they may adopt different roles: media commentators, specialized writers, amateur reporters. Media commentary is one of the most popular activities in the journalistic blogosphere. Such blogs, often called watchblogs, monitor the work of professional media online and offline to highlight under-covered stories, expose errors or bias in reporting, and to criticize poor arguments in editorials and columns.

For example, the US 2004 presidential elections provoked a snow-ball phenomenon of Republican and Democrat bloggers who decided to "adopt a journalist" to be closely 
watched during the campaign (Glaser, 2004). Single-purpose blogs were established to criticize political columnists. But the incident that created most debate thanks to weblogs was CBS's 60 minutes report on George W. Bush's military past. Republican bloggers argued that the documents shown in the TV report were fakes. The uproar finally led to a public apology by the leading reporter, Dan Rather, who acknowledged that they could not certify the authenticity of the documents (Kramer, 2004). In Spain, after the 11-M Madrid bombing (in March 2004), bloggers were the first to publicly claim that the communication policy of the government was one of "confusion" and to show that professional media were relying too much on official sources. The blogosphere became the meeting point for netizens' questions and fears. Professional media followed, but only after a while, and depending on their ideological backgrounds (López, 2004).

In some citizen weblogs, authors actually take the role of a reporter, even when the publisher him-/herself would not purposefully pretend to be substituting a journalist. In many cases, a personal weblog turns into first-hand reporting of an event that the blogger has accidentally witnessed. The London public transport bombings on July 7th 2005 brought the bloggers of the city to their weblogs to explain what they had seen and what they knew. Many offered camera-phone pictures that the media would not show because of ethical codes about avoiding images of wounded and dead people (Vara, 2005). During the Iraq War, a weblog by a pseudonym Salaam Pax became very famous and much debated (Zelizer and Allan, 2004:390). It appeared to be a blog created by someone witnessing the bombing of Baghdad in the midst of falling missiles. Some said that the blog was a CIA dis-information operation, but ultimately most were convinced that the "Baghdad blogger" existed, and he was actually later recruited as a columnist for the Guardian.

There are also much more sustained reporting efforts by bloggers, especially in two areas: There are specialists in a particular topic, discipline or industry, who share their interests and interpretations of its evolution, and there are amateur neighbourhood reporters, who offer chronicles on local events they have witnessed or been told about. For example, in the Kallio neighbourhood of Helsinki, Finland, there is a local weblog (Kallioblogi.com) that to a certain extent is a local news outlet. It contains reports, comments and debates on life and events in the neighbourhood, thus providing a micro-level public sphere. Specialist and neighbourhood bloggers can cover smaller stories that general purpose media overlook, but that are relevant to a specific audience (Lowrey, 2006:487).

Nonetheless, it is obvious that citizen-blog reporters do not possess the resources and standards of professional journalism (Lowrey, 2006). When assessing their blogs, it might be better to talk about "transparency" rather than fairness and accuracy (Blood, 2003:63). On the other hand, in the blogging culture, there is something resembling the ethics of journalism: "Blogging has the following virtues: candour, a sense of humour, intellectual honesty (in the sense of confessing immediately and openly to mistakes), and an openmindedness to different points of view" (Mooney, 2003). Thirty-five percent of US bloggers often include links to the original sources for their stories and state that they spend extra time checking the facts they want to include in a post (Lenhart and Fox, 2006). Nonetheless, citizen bloggers are not professional journalists. At best, they may complement the media in a valuable way, but they do not replace the media (Lasica, 2003).

While some authors stress the fact that most news-related blog content is based on commentary on stories produced by professional media, calling bloggers "parasitic" to journalism, others stress that there is a two-way relationship here: "In many ways, 
bloggers and journalists are in a mutually symbiotic relationship, working together to report, filter and break the news" (Hiler quoted in Bruns, 2005:212). Indeed, media journalists have started to appreciate the value of citizen journalists. More and more specialist and eyewitness blogs are being used by journalists as a source for news items. The blogosphere can be seen as an "early warning system" for journalists, providing material that can be turned into stories following the standards of fact-checking (Outing quoted in Shachtman, 2002).

\section{b) Audience Blogs: Journalistic Weblogs Written by the Public within the Media}

Online journalism experts have argued that media companies should incorporate public weblogs into their websites as one of a range of actions to promote a more reciprocal relationship with their audiences (Bowman and Willis, 2003:58). A space for audience blogs may promote a feeling of community among readers, foster dialogue between journalists and users, and, in the end, improve brand loyalty and trust. The popularity of weblogs has convinced some online media projects to add this weblog hosting feature. Depending on the case, they may be closely linked to the newsroom work, but most are just spaces for personal blogs that have nothing to do with current events and public debate, and therefore they might not redefine at all the core of the journalistic product they are embedded in. This type of journalistic weblog still needs much more experiences exploring its potential in order to assess its benefits and drawbacks for the mediaaudience relationship.

For instance, Le Monde (www.lemonde.fr), in France, opened up its website to online subscribers and places audience weblogs in the "Perspectives" section beside the opinion columns written by their journalists. In Spain, the free daily Qué marketed its launch in 2004, promising that part of its paper content would be taken from the audience blogs. In reality only two pages of the print edition are drawn from the weblogs, but the community created in the portal is growing steadily. Weblogs in QueDiario.com range from personal diaries to opinions on current events and local amateur reporting. In 2007, the Spanish leading quality paper El País (www.elpais.com) created an open blogging community for their readers, who were only required to accept very basic rules of decency in the postings. Other newspapers such as 20 Minutos in Spain or The Star Press in Indiana (USA) prefer to select their audience bloggers through a more controlled process, either a contest or an open call for proposals.

\section{c) Journalist Blogs: Journalistic Weblogs Written by Journalists Outside Media Institutions}

Professional journalists have been quickly seduced by the weblogs. They offer uncontrolled self-publishing space in which journalists can expand on issues and points of view that do not get into the media journalists work for. Weblogs allow complete editorial freedom and enable the journalist to adopt a much more interpretative or even opinionated position in comparison to the standards of mainstream media. News media companies are not always comfortable with this trend. CNN and Time (both owned by Time-Warner) asked two of their correspondents covering the the Iraq war to quit personal blogging. "CNN.com prefers to take a more structured approach to presenting the news ... We do not blog", argued a CNN spokesperson (Bowman and Willis, 2003:48). As the journalists were in Iraq at the expense of the media companies, they were told 
to concentrate on TV reporting. One of the journalists, Kevin Sites, was told to shut down his weblog the very day the war began, just 12 days after his blogging started. Sites eventually left $C N N$ and continued working in Iraq as a freelancer for $N B C$; and he resumed blogging some months later.

Besides these polemic cases, there are several journalists who write weblogs as a parallel activity to their media work without any troubles. In Finland, Matti Lintulahti (www.mattilintulahti.net), an executive of the magazine publishing company A-lehdet, discusses digital media trends in his Mediablogi, an approach to the blog similar to that of Matthew Buckland (www.matthewbuckland.com), the editor of Mail \& Guardian Online in South Africa. In Spain, a group of twenty local politics reporters in Tarragona have created a blog (salodelspenjats.blogspot.com) in which they report on anecdotes concerning the relationship between politicians and the press.

At the same time, some non-professional bloggers have taken the road to journalism through their continuous reporting activities. The former author of the blog FishbowlDC, Garrett Graff, former deputy press secretary of one of the Democrat precandidates for the 2004 US elections, in 2005 was the first blogger to get a White House press pass, a very symbolic step towards consolidation of journalistic weblogs. He wrote on political and media gossip around the centres of power in Washington, and ended up being editor at the weekly The Washingtonian.

\section{d) Media Blogs:Journalistic Weblogs Written by Journalists within Media Institutions}

A feasible option for media companies wishing to make use of weblogs is to set up weblogs for their journalists inside their media news websites. In this case, editorial control and stylistic requirements may not be as strict as in the news, but editors usually oversee the weblog entries as they are posted. These professionally produced journalistic blogs boomed after 2005. Among UK online newspapers, Hermida and Thurman (2007) noted an increase from 7 to 118 media weblogs between 2005 and 2006. Media companies are still exploring the possible uses of these in-house professional journalistic weblogs and do not always utilize the full range of features of a typical weblog. Comments, for example, are not allowed in some media weblogs, and others require the approval of a moderator in the online newsroom before being published, which can be seen as a conservative approach to a popular phenomenon: the appeal of the "blog" concept is being used, but while taming features that could challenge traditional journalistic routines: "News organizations may be more interested in containing and directing the blogging phenomenon than in fostering democratic participation" (Lowrey, 2006:493). Robinson (2007:79), in a content analysis of media weblogs, concluded that even though they are "a way for journalists to reclaim journalism online", countering the threat of independent weblogs, professional journalist bloggers give up some of the traditional routines in their media blogs, such as fact checking, and give room to subjectivity and rumour, thus challenging (but only to some extent) the traditional principles of journalism.

There are three different approaches to weblog use within the media:

1) Special events coverage. These blogs are born and die with the newsworthiness of the event. Electoral campaigns, major sports events and big impact breaking news stories are usual issues for these weblogs, but online media are starting to be active even in starting weblogs for unanticipated events such as terrorist attacks. Illustrative exam- 
ples are The Guardian's blogs on UK elections (www.guardian.co.uk), and, more specifically, the Spanish El Mundo's blog on the 2005 London bombings (www.elmundo.es). These blogs mainly exploit the immediacy and ease of publication of blogging, usually leaving opportunities for discussion aside.

2) Opinion columns. These take advantage of the fact that, in websites, the limits of paper and air time do not exist, and media can offer more permanent featured writers than they can offline. For instance, Italian La Reppublica (www.lareppublica.it) and American MSNBC.com have invited professional columnists and prestigious bloggers to express their opinions within their online publications. Such media blogs usually turn into public forums in cases where users can post comments. The position of the feature writer is the starting point of lively debates.

3) News commentary. In these blogs, correspondents or specialized journalists elaborate on the stories they produce for the main outlet, and publish notes and reflections that would not have room in the paper or the broadcast. In some cases, blog writers are hired specifically for the website. For example, in 2005 in Finland, the leading newspaper Helsingin Sanomat (www.hs.fi) started several media blogs with topics ranging from pet dogs to EU politics. Other examples are the thematic blogs on the Spanish broadcaster Telecinco's website covering cinema, politics, Formula 1, and journalism (www.telecinco.es).

The commentary weblog is taken further by some newsrooms and individual journalists, who use weblogs as a drafting space or a test bed for the news: The authors share points of view with their audience, likewise sources and details before actually writing the piece, and they get audience comments on how to develop the stories. One of the advocates of weblogs, veteran journalist Dan Gillmor, has argued that he bases his work on the idea that his readers always know more than he does, and a weblog is a tool to let them help him (Lasica, 2002b). The editors of the Dallas Morning News (www.dallasnews.com) assume that their blog, in which they comment on editorial decisions, increases transparency in news production. This strategy promotes an active dialogue with website visitors.

It appears that weblogs have created a new genre in institutionalized media journalism. The author is more visible and present in the story, and the style is more personal. To compensate for the fact that entries are not usually reviewed by an editor before publication, journalists tend to correct themselves transparently and quickly, reacting to reader's comments. Journalist bloggers say they feel as if they are doing a live radio programme: They pursue immediate analysis, impressionistic views of what is going on (Heyboer, 2004). Their experience suggests that blogging may not be appropriate for long in-depth analytical articles, but could be suitable for commentary, web digests, brief dispatches and follow-ups on developing events.

\section{Significance of Weblogs to Journalism}

Weblogs can be understood as a symbol or a sign of a general cultural trend that is turning the audience into an active producer of all sorts of content, from fan replicas of movie narratives to consumer reviews (Jenkins, 2004; Deuze, 2006). In this context, many weblogs on the Internet are irrelevant from the perspective of journalism. Just as they do on paper or other media, and in weblogs too, individuals and groups also pub- 
lish contents that represent literary forms other than journalism. Nevertheless, based on our examination on the various types of journalistically relevant blogs, we can conclude that weblogs, as a phenomenon, do seem to touch "the sphere of journalism" in several ways that are relevant to the future of the profession.

First, many weblogs openly challenge institutional or professional journalism by offering either competing or complementary information about news and current affairs. Wilson Lowrey points out that bloggers have exploited "jurisdictional vulnerabilities" of professional journalism to "poach" some types of information, such as "partisan expression, 'old stories', stories driven by non-elite sources, and highly specialized content" that institutional media neglected due to organizational constraints and standardized production schemes (2006:477). At the same time, "a number of weblog writers see their sites as instant critique of newspapers and television. Others have emphasized the speed with which weblogs have reported events, other praise the depth and thoroughness with which a network of webloggers has followed up a story" (Matheson, 2004a:452). According to Matheson, "such thinking values weblogging by bringing together conventional ideas of quality journalism as fact-based, up-to-the-moment and in-depth with the anti-establishment, anti-corporate liberalism of much commentary on the Internet" (ibid.). This poses another kind of a threat to established journalism than that originally assumed in the mid-1990s. Tom Regan (2003:69) has noted that "back then, the fear was that the Internet would take away huge chunks of readers ... from traditional media". But weblogs are doing something else: they "are demonstrating to traditional media [that] they no longer get to decide on their own what is news anymore" (ibid.). In other words, journalism's privilege of agenda-setting is being challenged, and the blogosphere is developing alternative current affairs agendas (Delwiche, 2005) collectively defined by bloggers and the social online tools they use to search and rank content (e.g. Digg, Technorati).

Second, weblogs "threaten to expose journalism at one of its weakest points - its lack of personal contact with readers" (Regan, 2003:69). Unlike institutional journalism, weblogs are essentially participatory. First of all, weblog stories are often published by people who themselves have been somehow involved in the events being reported. This is contradictory to the prevailing understanding that proper journalistic content is produced by "trained observers" (Singer, 2005:178), not by participants. Weblogs are often participatory also in the sense that they allow, indeed, invite their readers to converse about the issues being reported. In this way, weblogs "draw on idealizations of the Internet as a democratic space in which all social actors' voices may be heard, and where audiences become active public" (Matheson, 2004a:452). Applied to journalism, this participatory nature of weblogs shows that informing people about current affairs need not be objective in the sense of being estranged. Instead of lecturing, journalism can be conversational (Gillmor, 2004), and at the moment weblogs show one effective way of realizing this ideal.

The challenging nature and participatory features of weblogs lead us to the third dimension in which journalism and weblogs seem to meet: Weblogs question the "ownership" of journalism on the level of profession. Traditionally, journalism has been tied to certain organizational forms; journalism is what the media publish. Consequently, the dedicated paid labour force of the media industry, journalists, is considered to be the informally accredited purveyor of journalism. Since the invention of the term "gatekeeper", at the latest, deciding what the public needs to know, when and how has been an essential part of the professional role of journalists (Singer, 2005:178). The gate- 
keeper role is maintained and enforced by a set of professional routines and conventions that are said to constitute a sort of quality control mechanism in institutional journalism. However, exclusive rights to both gatekeeping and dedicated working practices are being taken away from professionalists and unashamedly adopted by weblog publishers. They are "...playing an active role in the process of collecting, reporting, sorting, analysing and disseminating news and information" (Lasica, 2003:71). In other words, the newcomers are performing largely the same routines as professional journalists. Bearing in mind that the journalistic profession is largely defined by practice, it seems that weblogs are challenging not only media institutions, but also professional journalists. While Lowrey (2006:483) suggests that the institutional apparatus of journalism guarantees some sort of control over the menace of bloggers, Singer (2007) proposes that new normative definitions of the profession based on ethical and philosophical principles are the only ones that can give journalism a raison d'être in the digital era.

Finally, we also have underscored that for some time now weblogs have not been something outside institutional media and its journalism. Several news media have included various kinds of weblogs in their online sites. In some cases, these are maintained by newsroom staff as a sort of dynamic columns that are updated frequently and contain texts with a more personal flavour than in other parts of the news site. In other cases, media weblogs are constructed as online spaces in which journalists and their audience can meet and engage in conversations about news issues. In this way, weblogs are also internally affecting the re-shaping of online journalism, thus offering examples of new available genres.

The evolution of blogging and online journalism is already mutually linked, but this is still an open process that has not yet shown many clear trends. The typology proposed here can be a useful tool for researchers who wish to explore: 1) the extent to which the challenges posed by weblogs to journalism as a profession are actually redefining the profession, 2) the influence of institutional contexts in the shaping of blogging as a journalistic genre, or 3) the tensions between editorial control and subjectivity in different kinds of journalistic blogs.

\section{References}

Blood, R. (2002) The Weblog Handbook: Practical Advice on Creating and Maintaining Your Blog. Cambridge, USA: Perseus.

Blood, R. (2003) 'Weblogs and Journalism: do they Connect?', Nieman reports 57(3):61-63. http:// www.nieman.harvard.edu/reports/03-3NRfall/V57N3.pdf

Bowman, S. and Willis, C. (2003) We Media, How Audiences are Shaping the Future of News and Information. Reston, VA: The Media Center at the American Press Institute. http://www.hypergene.net/ wemedia

Bruns, A. (2005) Gatewatching: Collaborative Online News Production. New York: Peter Lang.

Castells, M. (1996) The Rise of the Network Society. Malden, Mass.: Blackwell Publishers.

Delwiche, A. (2005) 'Agenda-setting, opinion leadership, and the world of Web logs', First Monday 10(12). http://firstmonday.org/issues/issue10_12/delwiche/index.html

Deuze, M. (2005) 'Towards Professional Participatory Storytelling in Journalism and Advertising', First Monday 10(7). http://firstmonday.org/issues/issue10_7/deuze/index.html

\section{Acknowledgement}

An initial version of this paper was presented at the 2006 COST A20 Conference in Delphi, Greece. We are grateful for the helpful comments made by participants. 
Deuze, M. (2006) 'Participation, Remediation, Bricolage: Considering Principal Components of a Digital Culture', The Information Society 22:63-75.

Domingo, D. (2006) Inventing Online Journalism: Development of the Internet as a News Medium in Four Catalan Online Newsrooms. Barcelona: Universitat Autonoma de Barcelona. http://www.tesisenxarxa. net/TDX-1219106-153347/index.html

Fidler, R. (1997) Mediamorphosis: Understanding New Media. Thousand Oaks, Ca.: Pine Forge Press.

Fulton, K. (1996) 'A Tour of Uncertain Future', Columbia Journalism Review. http://archives.cjr.org/year/ 96/2/tour9.asp

Gillmor, D. (2004) We the Media. Grassroots Journalism by the People, for the People. Sebastopol, USA: O'Reilly. http://www.authorama.com/we-the-media-1.html

Glaser, M. (2004) 'Watchblogs Put the Political Press Under the Microscope', Online Journalism Review. http://ojr.org/ojr/glaser/1076465317.php

Heinonen, A. (1999) Journalism in the Age of the Net: Changing Society, Changing Profession. Tampere: University of Tampere. http://acta.uta.fi/pdf/951-44-5349-2.pdf

Hermida, A. and Thurman, N. (2007) 'Comments Please: How the British News Media are Struggling with User-generated Content', paper presented at the International Symposium on Online Journalism, Austin, Texas. http://journalism.utexas.edu/onlinejournalism/2007/papers/Hermida.pdf

Heyboer, K. (2004) 'Bloggin' in the Newsroom', American Journalism Review. http://www.ajr.org/ Article.asp?id=3473

Hyde, G. (2002) 'Independent Media Centers: Cyber-Subversion and the Alternative Press', First Monday 7(4). http://firstmonday.org/issues/issue7_4/hyde/index.html

Jenkins, H. (2004) 'The Cultural Logic of Media Convergence', International Journal of Cultural Studies $7(1): 33-43$.

Kramer, S. (2004) 'CBS Scandal Highlights Tension Between Bloggers and News Media', Online Journalism Review. http://ojr.org/ojr/workplace/1096589178.php

Kunelius, R. (2001) 'Conversation: a Metaphor and a Method for Better Journalism?', Journalism Studies 2(1):31-54.

Lasica, J.D. (2002a) 'When Bloggers Commit Journalism', Online Journalism Review. http://www.ojr.org/ ojr/lasica/1032910520.php

Lasica, J.D. (2002b) 'Weblogs: A New Source of News', Online Journalism Review. http://www.ojr.org/ojr/ workplace/1017958782.php

Lasica, J.D. (2003) 'Blogs and Journalism Need Each Other', Nieman Reports. 57(3):70-74. http:// www.nieman.harvard.edu/reports/03-3NRfall/V57N3.pdf

Lenhart, A. and Fox, S. (2006) Bloggers: A Portrait of the Internet's New Storytellers. Washington: PEW Internet. http://www.pewinternet.org/pdfs/PIP Bloggers Report July 19 2006.pdf

López, G. (2004) 'El 11-M y el proceso de formación de la opinión pública en situaciones de crisis' [The Madrid bombing and the process of public opinión formation in crisis situations]. Proceedings of the II Online Congress for the Observatory of the Cybersociety. http://www.cibersociedad.net/congres2004/grups/fitxacom_publica2.php?id=227

Lowrey, W. (2006) 'Mapping the Journalism-blogging Relationship', Journalism 7(4): 477-500.

Matheson, D. (2004a) 'Weblogs and the Epistemology of the News: Some Trends in Online Journalism', New Media \& Society 6(4): 443-468.

Matheson, D. (2004b) 'Negotiating Claims to Journalism: Webloggers' Orientation to News Genres', Convergence 10(4): 33-54.

Mooney, Ch. (2003) 'How Blogging Changed Journalism - Almost', Pittsburgh Post-Gazette. http:// www.post-gazette.com/forum/comm/20030202edmoon02p1.asp

Paul, N. (2005) 'NNew News' Retrospective: Is Online News Reaching its Potential?', Online Journalism Review. http://www.ojr.org/ojr/stories/050324paul

Platon, S. and Deuze, M. (2003) 'Indymedia Journalism: A Radical Way of Making, Selecting and Sharing News?', Journalism 4(3): 336-355.

Regan, T. (2003) 'Weblogs Threaten and Inform Traditional Journalism', Nieman Reports 57(3): 68-69. http://www.nieman.harvard.edu/reports/03-3NRfall/V57N3.pdf

Robinson, S. (2006) 'The Mission of the j-blog: Recapturing Journalistic Authority Online', Journalism 7(1): 65-83.

Schaffer, J. (2007) Citizen Media: Fad or the Future of News? Maryland: J-Lab, the Institute for Interactive Journalism. http://www.kcnn.org/research/citizen_media_report/

Shachtman, N. (2002) 'Blogs make the headlines', Wired, http://www.wired.com/news/culture/0,1284, $56978,00$. html

Singer, J.B. (2005) 'The Political j-blogger. 'Normalizing' a New Media Form to Fit Old Norms and Practices', Journalism 6(2): 173-198. 
Singer, J.B. (2006) 'The Socially Responsible Existentialist: A Normative Emphasis for Journalists in a New Media Environment', Journalism Studies 7(1): 2-18.

Sirkkunen, E. and Kotilainen, S. (eds.) (2004) Towards Active Citizenship on the Net. Possibilities of Citizen Oriented Communication: Case Studies from Finland. Tampere: University of Tampere. http:/ /tampub.uta.fi/index.php?tiedot=58

Stauffer, T. (2002) Blog on. The Essential Guide to Building Dynamic Weblogs. Berkeley, California: McGraw-Hill.

Vara, V. (2005) 'Bloggers and Photographers Chronicle Chaos in London', The Wall Street Journal Online (7 July). http://www.wsj.com

Van der Wurff, R. and Lauf, E. (eds.) (2005) Print and Online Newspapers in Europe. A Comparative Analysis in 16 Countries. Amsterdam: Het Spinhuis.

Zelizer, B. and Allan, A. (2004) Reporting War: Journalism in Wartime. London: Routledge.

DAVID DOMINGO, Ph.D., Visiting Assistant Professor, School of Journalism and Mass Communication, University of Iowa, and Assistant Professor, Department of Communication, Universitat Rovira i Virgili, Sant Pau 4, 43003 Tarragona, Catalonia, david.domingo@urv.cat

ARI HEINONEN, D.Soc.Sc., Senior Lecturer, Department of Journalism and Mass Communication, FI-33014 University of Tampere, ari.a.heinonen@uta.fi 